\title{
\begin{tabular}{l|l}
\hline Received July 13, 1999 \\
\hline
\end{tabular}
}

Original Accepted for Publication January 14, 2000

(C) 2000 Soc. Mater. Eng. Resour. Japan

\section{Kinetics of Barium Titanate Formation from Wet Chemically Derived Precursor}

\author{
Katsuyasu SUGAWARA*, Tomomichi NISHINO*, Takuo SUGAWARA*, \\ Tomoyoshi SHOJI* and Kazutaka MAKINO* \\ *Faculty of Engineering and Resource Science, Akita University \\ 1-1 Tegata Gakuen-cho, Akita City, Akita Pref. 010-8502 Japan \\ E-mail :katsu@ipc.akita-u.ac.jp
}

\begin{abstract}
In a series of studies of fundamental study on the kinetics of electroceramics processing by wet chemical methods, change in composition with temperature and reaction time for barium titanyl oxalates tetrahydrates in the cacination were characterized. Rapid formation of barium titanante was observed above $823 \mathrm{~K}$, which resulted from the reaction between titania and barium carbonate or barium oxide(s). A kinetic model was proposed based on the experimental results. Thermogravimetric change of barium titanyl oxalates tetrahydrates during calcination could be reproduced and dynamics of barium titanate formation was successfully simulated using these kinetic parameters.
\end{abstract}

Key Word : Barium titanate, Calcination, Electroceramics, Kinetics, Wet chemical method

\section{Introduction}

Barium titanate $\left(\mathrm{BaTiO}_{3}\right)$ is a typical dielectric ceramic widely utilized for multilayer ceramic capacitors, PTC thermistors and electro-optic components. Conventional processing of barium titanate depends on solid-state reaction between barium carbonate and titanium oxide powders ${ }^{1)}$. However, problems arise with this conventional method because raw materials and ball-milling operations introduce undesirable impurities such as alumina, silica and phosphorous. These impurities cause extraordinary crystalline growth, inhomogeneous microstructure and poor dielectric properties of sintered barium titanate ${ }^{2)}$.

Wet chemical route is one of promising methods for electroceramic preparation to yield low temperature sintering and high purity, homogeneous and ultrafine powders with stoichiometric precision which contributes to stable electric characteristics ${ }^{3-7)}$. Homogeneous grain growth with narrow size distribution has been reported for the preparation of barium titanate from oxalate though the powders from wet-chemical methods generally have low compact density. In Japan, 200 ton/month of barium titanyl oxalate is now utilizing for manufacturing 120 billion of multilayer capacitors per month.

Barium titanate is formed by calcination and firing of the precursor. Heat treatment condition (temperature history and atmosphere etc.) of oxalate precursor affects particle size distribution, compact and sintering behavior of high grade barium titanate powder. While there have been many studies of pyrolysis behavior of precursors reported, there have not been any quantitative and kinetic investigations carried out.

In a series of the fundamental kinetic studies of electroceramic processing by wet chemical methods ${ }^{8)}$, calcination of barium titanyl oxalates $\left(\mathrm{BaTiO}\left(\mathrm{C}_{2} \mathrm{O}_{4}\right)_{2} \cdot 4 \mathrm{H}_{2} \mathrm{O}\right)$ was investigated. Change in composition with temperature and reaction time for the barium titanyl oxalates in the calcination were characterized by Fourier transform infrared spectroscopy, thermogravimetry with differential thermal analysis, X-ray diffraction, and an acid extraction. Thermogravimetric change of barium titanyl oxalates and formation behavior of barium titanate in the calcination process were successfully simulated assuming a reaction scheme based on experimental results.

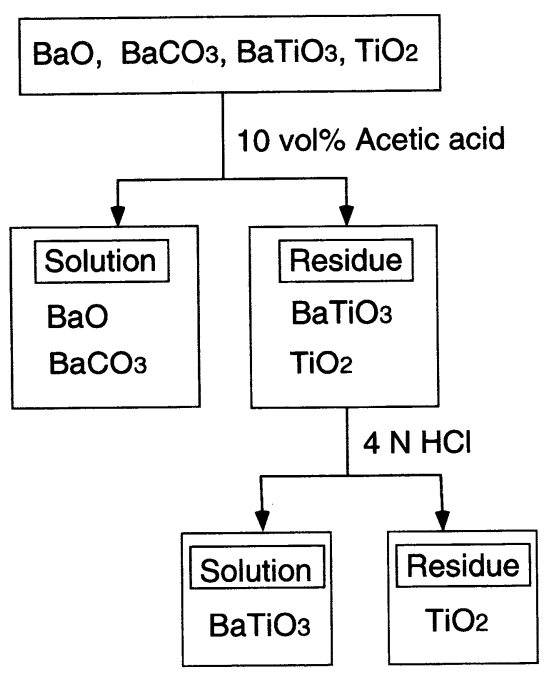

Figure. 1 Acid extraction method 


\section{Experimental}

Barium titanyl oxalates tetrahydrates $\mathrm{BaTiO}\left(\mathrm{C}_{2} \mathrm{O}_{4}\right)_{2} \cdot 4 \mathrm{H}_{2} \mathrm{O}$ (Jun-sei Kagaku, JT-1) was used without further purification. The aggromerated sample was crushed to -200 mesh and then supplied to analysis and experiments.

The sample was calcined at various final temperatures up to $1473 \mathrm{~K}$ with a heat-up rate of $5 \mathrm{~K} / \mathrm{min}$ in air. The calcination process of the sample was characterized by Fourier transform infrared spectroscopy (Bomem DA3), thermogravimetry with differential thermal analysis (Rigaku TAS 200) and X-ray diffraction (Rigaku CN155D6). The content of barium titanate in the calcined sample was determined after extraction with acetic and hydrochloric acids shown in Fig. 1. The present analysis is based on the fact that barium oxide and barium carbonate dissolve in acetic acid, while barium titanate dissolves in hydrochloric acid but not acetic acid ${ }^{9)}$. Preliminary experiments indicated that the extraction could be completed in $2 \mathrm{~h}$ with $10 \mathrm{vol} \%$ acetic acid and $4 \mathrm{M}$ hydrochloric acid at $333 \mathrm{~K}$. The barium ion in the filtrate was determined gravimetrically after precipitation of barium sulfate by addition of ammonium sulfate.

\section{Results and Discussion}

\subsection{Change in composition with calcination}

Figure 2 shows the change in FT-IR spectra of barium titanyl

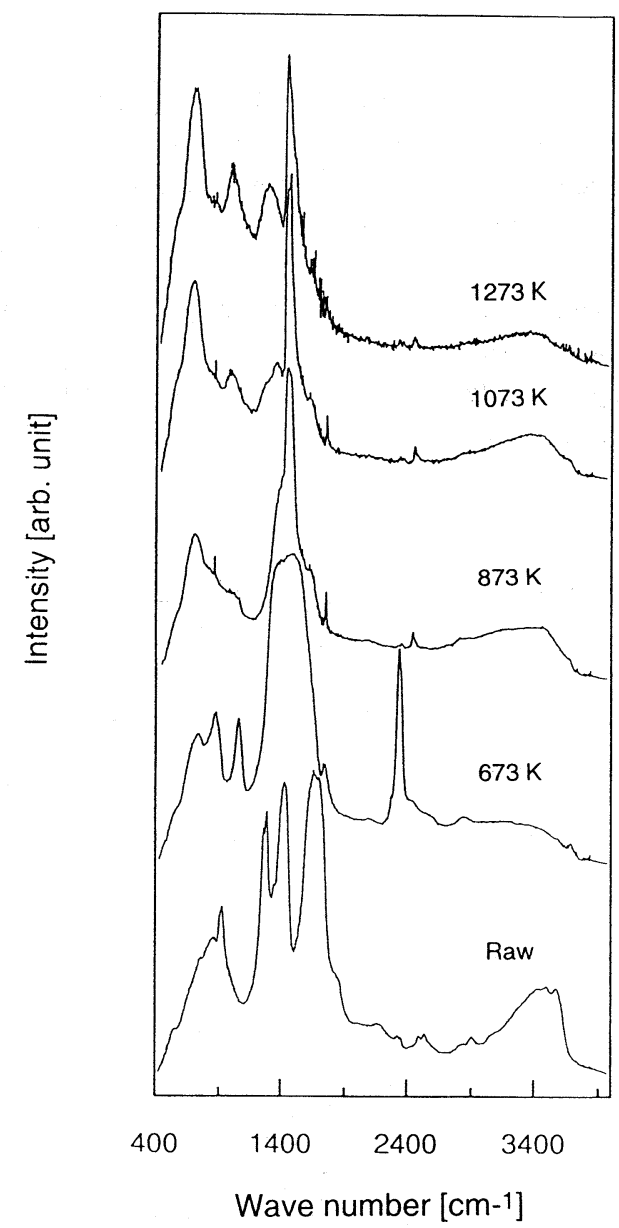

Figure. 2 Change of FTIR-PA spectra of $\mathrm{BaTiO}\left(\mathrm{C}_{2} \mathrm{O}_{4}\right)_{2} \cdot 4 \mathrm{H}_{2} \mathrm{O}$ with calcined temperature (Heating rate $5 \mathrm{~K} / \mathrm{min}$, holding time ; 2 h) oxalates tetrahydrates with calcination temperature. The sample was calcined with TG-DTA apparatus by heating up at a rate of 5 $\mathrm{K} / \mathrm{min}$, followed by $2 \mathrm{~h}$ of holding time at a specified terminal temperature from 673 to $1273 \mathrm{~K}$ in air. The spectrum of raw sample shows the peaks at $1270 \mathrm{~cm}^{-1}, 1420 \mathrm{~cm}^{-1}$ and $1640 \mathrm{~cm}^{-1}$ which resulted from $\mathrm{CO}$ and $\mathrm{COO}$ groups. These peaks and a peak at $3200 \mathrm{~cm}^{-1}$ attributable to hydroxyl group disappeared in the sample calcined at $673 \mathrm{~K}$. The spectrum of the sample calcined at $673 \mathrm{~K}$ showed the three peaks of $870 \mathrm{~cm}^{-1}, 1060 \mathrm{~cm}^{-1}$ and 1420 $\mathrm{cm}^{-1}$ attributable to barium carbonate. Barium titanyl oxalates tetrahydrates was changed to barium carbonate while dehydration and pyrolysis of oxalate group were occurred. Formation of barium oxide(s) and barium titanate was observed from the peaks at $1430 \mathrm{~cm}^{-1}$ and $680 \mathrm{~cm}^{-1}$, respectively.

The results of thermogravimetric and thermal differential analyses of barium titanyl oxalates tetrahydrates is shown in Fig. 3. The thermogravimetric curve indicates large three-steps weight loss ${ }^{10}$. The first large weight loss with endothermic peak corresponded to dehydration while the sample was heated up to $473 \mathrm{~K}$. The second

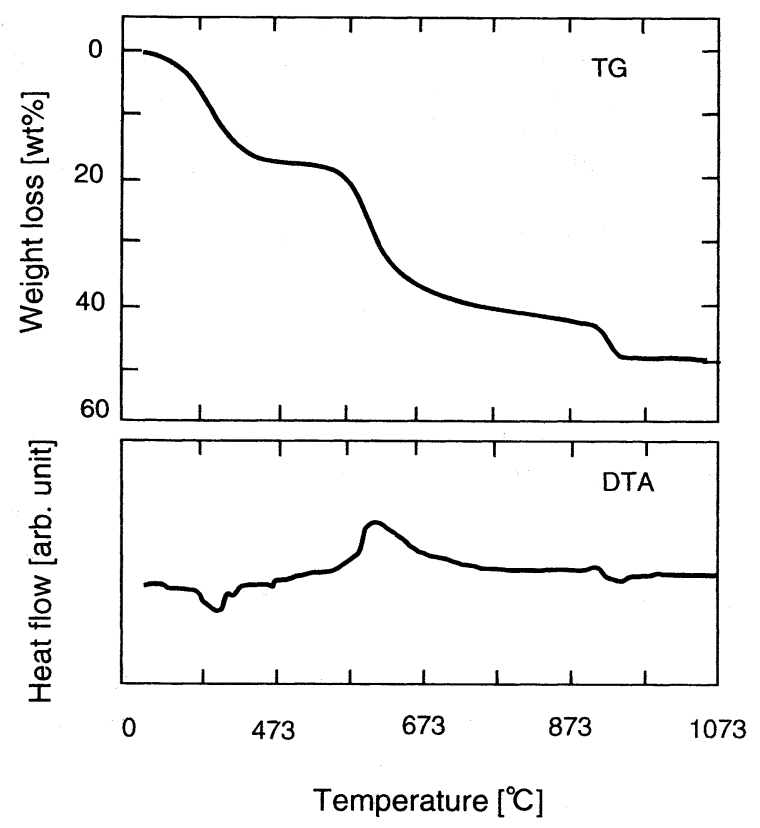

Figure. 3 TG-DTA curves of $\mathrm{BaTiO}\left(\mathrm{C}_{2} \mathrm{O}_{4}\right)_{2} \cdot 4 \mathrm{H}_{2} \mathrm{O}$ (Heating rate $; 5 \mathrm{~K} / \mathrm{min}$ )

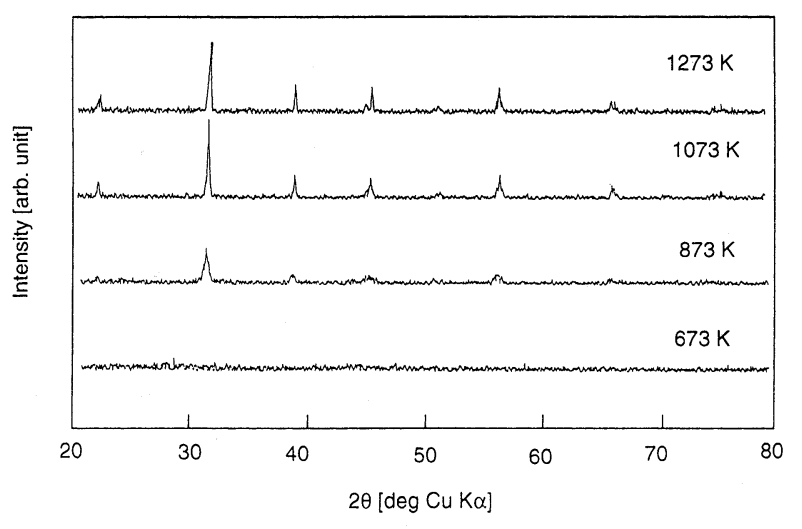

Figure. 4 XRD patterns of calcined samples (Heating rate ; $5 \mathrm{~K} / \mathrm{min}$, holding time ; $2 \mathrm{~h}$ ) 
weight loss with exothermic peak from $573 \mathrm{~K}$ to $673 \mathrm{~K}$ resulted from decomposition of barium titanyl oxalates to barium carbonate, barium oxide(s) and titanium oxide. The formation of barium titanate caused the third weight loss with endothermic peak in the temperature range from $873 \mathrm{~K}$ to $973 \mathrm{~K}$.

In Figure 4, the change of XRD patterns with temperature is shown for barium titanyl oxalates tetrahydrates calcined at 5 $\mathrm{K} /$ min up to $1273 \mathrm{~K}$. Three XRD patterns were obtained at room temperature for the quenched samples after calcination. While the sample was amorphous below $673 \mathrm{~K}$, peak intensity corresponding to barium titanate increased above $873 \mathrm{~K}$. The only peaks found in $\mathrm{XRD}$ analysis were those for barium titanate.

Figure 5 shows change with calcination temperature of barium titanate content determined by the acid-extraction method. A heating rate of $5 \mathrm{~K} / \mathrm{min}$ was used in these experiments along with a holding time of $2 \mathrm{~h}$ at a specified terminal temperature. Barium titanate formed rapidly from $773 \mathrm{~K}$ and barium titanate yield reached $80 \%$ at $873 \mathrm{~K}$. A moderate increment in yield was observed above $923 \mathrm{~K}$.

\section{2 Rate analysis}

Based on the preceding results, the following reaction scheme is proposed for calculation of barium titanyl oxalates tetrahydrates :

$\begin{array}{lll}\operatorname{BaTiO}\left(\mathrm{C}_{2} \mathrm{O}_{4}\right)_{2} \cdot 4 \mathrm{H}_{2} \mathrm{O} & k_{1} & \\ & k_{2} & \mathrm{BaTiO}\left(\mathrm{C}_{2} \mathrm{O}_{4}\right)_{2} \\ \mathrm{BaTiO}\left(\mathrm{C}_{2} \mathrm{O}_{4}\right)_{2} & \rightarrow \mathrm{BaCO}_{3}+\mathrm{TiO}_{2} \\ & k_{3} \\ \mathrm{BaTiO}\left(\mathrm{C}_{2} \mathrm{O}_{4}\right)_{2} & \rightarrow \mathrm{BaO} \text { or } \mathrm{BaO}_{2}+\mathrm{TiO}_{2} \\ \mathrm{BaCO}_{3}+\mathrm{TiO}_{2} & \rightarrow \mathrm{kaTiO}_{4} \\ & k_{5}\end{array}$

$\mathrm{BaO}$ or $\mathrm{BaO}_{2}+\mathrm{TiO}_{2} \rightarrow \mathrm{BaTiO}_{3}$

Now it is assumed that decomposition and formation rates are expressed by following first-order kinetic model equations. Dehydration rate of $\mathrm{BaTiO}\left(\mathrm{C}_{2} \mathrm{O}_{4}\right)_{2} \cdot 4 \mathrm{H}_{2} \mathrm{O}$ is expressed by Eq.(6).

$$
d\left[\mathrm{BaTiO}\left(\mathrm{C}_{2} \mathrm{O}_{4}\right)_{2} \cdot 4 \mathrm{H}_{2} \mathrm{O}\right] / d t=-k_{1}\left[\mathrm{BaTiO}\left(\mathrm{C}_{2} \mathrm{O}_{4}\right)_{2} \cdot 4 \mathrm{H}_{2} \mathrm{O}\right]
$$

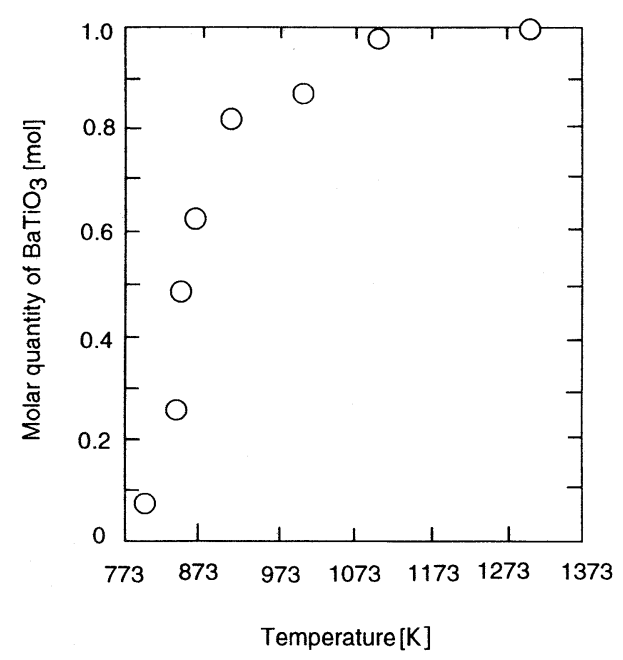

Figure. 5 Change in $\mathrm{BaTiO}_{3}$ yield with temperature (Heating rate $; 5 \mathrm{~K} / \mathrm{min}$, holding time at a specified temperature ; $2 \mathrm{~h}$ )
An Arrhenius-type temperature dependency is also assumed for the rate constants in this study.

$$
k_{i}=k_{i 0} \exp \left(-E_{i} / R T\right)
$$

Temperature history and initial conditions are given by Eqs.(8) and (9).

$$
\begin{aligned}
& d T / d t=m \quad(m=5 \mathrm{~K} / \mathrm{min}) \\
& {\left[\mathrm{BaTiO}\left(\mathrm{C}_{2} \mathrm{O}_{4}\right)_{2} \cdot 4 \mathrm{H}_{2} \mathrm{O}\right]=1, \quad\left[\mathrm{BaTiO}\left(\mathrm{C}_{2} \mathrm{O}_{4}\right)_{2}\right]=0} \\
& T=T_{0} \text { at } t=0
\end{aligned}
$$

Formation and decomposition rate of $\mathrm{BaTiO}\left(\mathrm{C}_{2} \mathrm{O}_{4}\right)_{2}$ is expressed by Eq.(10).

$$
\begin{array}{r}
d\left[\mathrm{BaTiO}\left(\mathrm{C}_{2} \mathrm{O}_{4}\right)_{2}\right] / d t=k_{1}\left[\mathrm{BaTiO}\left(\mathrm{C}_{2} \mathrm{O}_{4}\right)_{2} \cdot 4 \mathrm{H}_{2} \mathrm{O}\right] \\
-\left(k_{2}+k_{3}\right)\left[\mathrm{BaTiO}\left(\mathrm{C}_{2} \mathrm{O}_{4}\right)_{2}\right]
\end{array}
$$

Barium titanate is formed by reaction of barium carbonate or barium oxide(s) with titanium oxide. The formation rate of barium titanate is given by Eq.(11).

$d\left[\mathrm{BaTiO}_{3}\right] / d t=k_{4}\left[\mathrm{BaCO}_{3}\right]\left[\mathrm{TiO}_{2}\right]+k_{5}[\mathrm{BaO}(\mathrm{s})]\left[\mathrm{TiO}_{2}\right]$

Material balances for barium carbonate and barium oxide(s) are given by following equations.

$$
\begin{aligned}
& d\left[\mathrm{BaCO}_{3}\right] / d t=k_{2}\left[\mathrm{BaTiO}\left(\mathrm{C}_{2} \mathrm{O}_{4}\right)_{2}\right]-k_{4}\left[\mathrm{BaCO}_{3}\right]\left[\mathrm{TiO}_{2}\right] \\
& d[\mathrm{BaO}(\mathrm{s})] / d t=k_{3}\left[\mathrm{BaTiO}\left(\mathrm{C}_{2} \mathrm{O}_{4}\right)_{2}\right]-k_{5}[\mathrm{BaO}]\left[\mathrm{TiO}_{2}\right] \\
& {\left[\mathrm{BaTiO}\left(\mathrm{C}_{2} \mathrm{O}_{4}\right)_{2}\right]=[\mathrm{BaCO}]=[\mathrm{BaO}(\mathrm{s})]=0 \quad \text { at } t=0}
\end{aligned}
$$

Figure 6 shows observed and calculated thermogravimetric

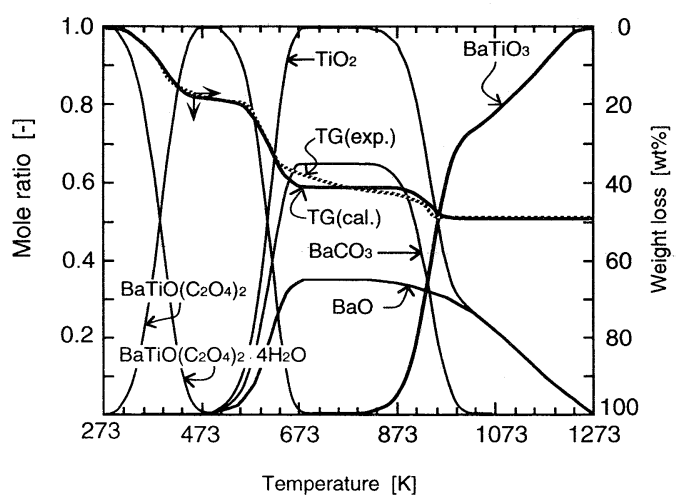

Figure. 6 Observed and simulated TG curves of barium titanyl oxalate

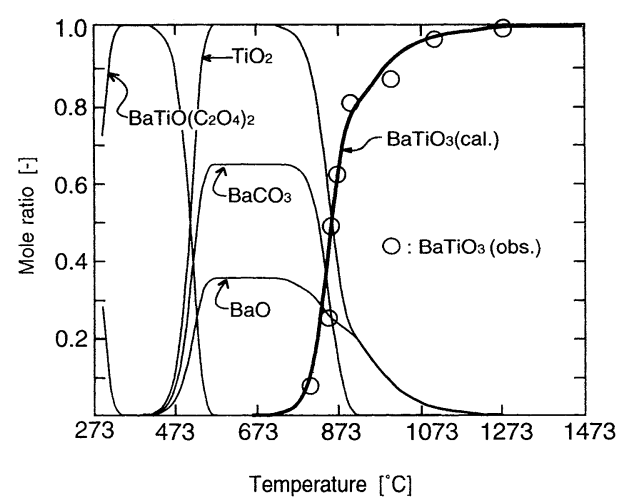

Figure. 7 Observed and simulated values of barium titanate formation

(Holding time at a specified terminal temperature of $2 \mathrm{~h}$ ) 
changes of $\mathrm{BaTiO}\left(\mathrm{C}_{2} \mathrm{O}_{4}\right)_{2} \cdot 4 \mathrm{H}_{2} \mathrm{O}$ heated up to $1273 \mathrm{~K}$. As indicated in this figure, the observed thermogravimetric curve of $\mathrm{BaTiO}\left(\mathrm{C}_{2} \mathrm{O}_{4}\right)_{2} \cdot 4 \mathrm{H}_{2} \mathrm{O}$ was successfully simulated. The determined kinetic parameters are :

$$
\begin{aligned}
& k_{10}=200 \mathrm{~min}^{-1}, E_{1}=7.1 \mathrm{kcal} \cdot \mathrm{mol}^{-1} \\
& k_{20}=1.5 \times 10^{6} \mathrm{~min}^{-1}, E_{2}=22 \mathrm{kcal} \cdot \mathrm{mol}^{-1} \\
& k_{30}=8.0 \times 10^{5} \mathrm{~mol}^{-1} \cdot \mathrm{min}^{-1}, E_{3}=22 \mathrm{kcal} \cdot \mathrm{mol}^{-1} \\
& k_{40}=5.0 \times 10^{13} \mathrm{~mol}^{-1} \cdot \mathrm{min}^{-1}, E_{4}=65 \mathrm{kcal} \cdot \mathrm{mol}^{-1} \\
& k_{50}=2.0 \times 10^{5} \mathrm{~mol}^{-1} \cdot \mathrm{min}^{-1}, E_{5}=34 \mathrm{kcal} \cdot \mathrm{mol}^{-1}
\end{aligned}
$$

Figure 7 shows observed and simulated change with cacination temperature of barium titanate content. Solid lines in Fig. 6 indicate simulated changes of barium titanate and other components. Barium titanate formation has been successfully simulated using the kinetic parameters. The simulation indicates that the rapid formation of barium titanate resulted from the reaction between barium carbonate and titanium oxide at the temperatures up to 973 $\mathrm{K}$. On the other hand, the reaction between barium oxide(s) and titanium oxide plays a role of moderate formation of barium titanate without weight loss in thermogravimetric change above $973 \mathrm{~K}$.

\section{Conclusions}

Changes in composition with temperature for barium titanyl oxalates tetrahydrates in the calcination were characterized by FTIR, TG-DTA, XRD and acid extraction. Thermogravimetric change and formation behavior of barium titanate were successfully simulated assuming a reaction scheme based on experimental results and volume reaction model. The simulated results indicated that barium titanate formed rapidly by the reaction of barium carbonate and titanium oxide at the temperatures up to $973 \mathrm{~K}$, and moderate formation of barium titanate above $973 \mathrm{~K}$ resulted from the reaction between barium oxide(s) and titanium oxide.

\section{Acknowledgments}

The authors are grateful to the Electronic Device Division of TDK Corp. for financial support.

\section{References}

1) Beauger, A., J. C. Mutin, and C. Niepce, "Synthesis Reaction of Metatitanate $\mathrm{BaTiO}_{3}$ : Part 1, Effect of the Gaseous Atmo sphere upon the Thermal Evolution of the System $\mathrm{BaCO}_{3}-\mathrm{Ti}$ $\mathrm{O}_{2}{ }^{\prime \prime}$, J. Mater. Sci., 18, 3041-46 (1983)

2) Phule, P. and S. Risbud, "Low-temperature Synthesis and Processing of Electronic Materials in the $\mathrm{BaO}-\mathrm{TiO}_{2}$ System", $J$. Mater. Sci., 25, 1169-1183 (1990)

3) Gallagher, P. K., F. Schrey, and F. V. DiMarcello, "Preparation of Semiconducting Titanates by Chemical Methods", J. Am. Ceram. Soc., 46, 359-65 (1963)

4) Gallagher, P. K. and J. Thomson, Jr., "Thermal Analysis of Some Barium and Strontium Titanyl Oxalates", J. Am. Ceram. Soc., 48, 644-647 (1965)

5) Kajiyoshi, K., N. Ishizawa, and M. Yoshimura, "Preparation of Tetragonal Barium Titanate Thin Film on Titanium Metal Substrate by Hydrothermal Method", J. Am. Ceram. Soc., 74, 369-74 (1991)

6) Kasai, T., Y. Ozaki, and S. Yamamoto, "Preparation of BaTi $\mathrm{O}_{3}$ and $\mathrm{SrTiO}_{3}$ from Metal Alkoxides", Yogyo Kyokaishi, 95, 1000 (1987)

7) Kirby, K. W., "Alkoxide Synthesis Techniques for $\mathrm{BaTiO}_{3}$ ", Mater. Res. Bull., 23, 881-90 (1988)

8) Sugawara, K., Sakusabe, H., Nishino, T., Sugawara, T. and Dranoff, J., "Thermal Decomposition of Barium Titanate Precursor Prepared by a Wet Chemical Method", AIChE J., 43, 2837-2843 (1997)

9) Kubo, K. and K. Shinriki, "Synthesis of Barium Titanate", Titanium, 8, 136 (1960)

10) Swilam, M. N. and A. M. Gadalla, "Decomposition of Barium Titanyl Oxalate and Assessment of Barium Titanate Produced at Various Temperatures", J. Brit. Ceram. Soc., 74, 159-163 (1973) 